\title{
Case-based reasoning approach to Adaptive Web-based Educational Systems
}

\author{
Paulo Alves \\ Instituto Politécnico de Bragança \\ palves@ipb.pt
}

\author{
Luís Amaral \\ Universidade do Minho \\ amaral@dsi.uminho.pt
}

\author{
José Pires \\ Instituto Politécnico de Bragança \\ adriano@ipb.pt
}

\begin{abstract}
Virtual learning environments systems are based on the classroom paradigm, in which the knowledge is transmitted for all the students in the same way.

To enhance e-learning, adapting the contents to the needs of each student is essential, and a more personalized learning support is required. The adoption of pedagogical agents and new artificial intelligence methodologies can response to the needs of individual students and provide a more effective collaboration in virtual learning environments.

The learning experience of each student can be adapted to others students with the same characteristics. The adaptation of past cases to solve new problems is one of the features of case-based reasoning methodology, which can provide an effective knowledge transmission, based on learning activities.

In this paper, we present a case-based reasoning approach to Adaptive Web-based Educational Systems using fuzzy logic to adapt e-learning contents and contexts according to the student learning style and individual needs.
\end{abstract}

\section{Introduction}

The Bologna Process, has the main goal to establish a European Higher Education Area by 2010. The institutions are faced with new challenges in the structural change on curricula and the adoption of innovative teaching and learning processes.

To face this challenge, the curricula design must be based on learning outcomes and less in the classical teaching model, integrating e-learning technologies and new pedagogical models.

The pedagogical model is centered on the student and the lecturer has the mission to support the learning process in the contact hours as so at distance using information and communication technologies.
To improve the learning process and facilitate the student support, we propose the adoption of agents in Adaptive Web-based Educational Systems, with the mission to support the student in their learning activities, coaching, advertising for difficulties, and adapting contents and contexts according to each student learning path.

\section{Case-Based Reasoning}

Case-based reasoning (CBR) is one of the major reasoning paradigms in artificial intelligence, with applications in several research areas like healthcare, education, business, legal reasoning, and manufacturing. Kolodner [1] defined CBR as adapting old solutions to meet new demands.

CBR has the advantage of the low initial training of the system, compared with other expert systems like rule-based reasoning [2]. In CBR the relation of the problems with their solutions is obtained from experiences and the system can start operate with few stored cases.

The problem-solving life cycle in a CBR systems described by Aamodt and Plaza [3] consists essentially of the following four parts: retrieving similar cases experienced in the past, reusing the cases copying or integrating the solutions from the cases retrieved, revising or adapting the solution(s) and retaining the new validated solution

The use of CBR in education has several advantages like supporting the lecturers in the design of learning activities or to improve the student's knowledge.

We use this approach in educational agents, using the past cases to solve new problems in the learning process. This agent has the characteristic of an advisor that alerts the student for all the events, coaching the student and coordinating the collaborative activities. The agent has also the mission to support the student in the agenda management, assessment, project 
management and in the recommendation of Web resources.

\section{Case-Based Reasoning Approach to Adaptive Web-based Educational Systems}

One of the first applications of artificial intelligence techniques in education it was the Intelligent Tutoring Systems (ITS). Kearsley defined an intelligent tutoring system as an application of artificial intelligence techniques to teach students [4].

With the expansion of E-learning, to overcome the limitation of "one size fits all" of current e-learning systems, Brusilovsky propose the adoption of Adaptive Web-based Educational Systems [5], supported in the theory of Adaptive Hypermedia Systems. These systems explore the features of Web based collaboration with the adaptation features of intelligent tutoring systems.

Brusilovsky argues that the most important challenge of Adaptive Web-based Educational Systems is the combination of the features of learning management systems with adaptive content authoring tools.

To address this, we propose the integration of casebased reasoning agents to adapt the contents to the student's needs, improving and sharing the knowledge between students based on learning management systems.

With the mission to improve the student knowledge, and to supply a more effective learning process, according to the Bologna goals, we integrate in our learning management system agents based on casebased reasoning theory. The Domus agent is a CBR tutoring agent with the mission to support the student in the learning process, using previous experience to solve new cases.

The CBR retrieving method is based on Fuzzy logic, extracting the most similar cases based on the learning style and profile of the students, taking in consideration the interest and the complexity of the learning unit and learning activity.

With Fuzzy approach we can find similar cases of the current learning activity, extracting notes, forum posts and Web resources related to the activity. To enhance the learning interactivity, the agent highlights parts of the document, based on the possibility of difficulties that match the present case.

The annotation tool of web documents is an important part of the architecture, because the behavior of the Domus agent is based on the insertion of notes and difficulties in contents.

When the student is performing the learning activity, the Domus agent search for similar cases in the database, based on CBR methodology. The similarity of cases is based on student learning style, the collaboration in the learning process and the learning outcomes. This approach, assumes that the students with similar profile have similar difficulties in the learning process.

The Domus agent, based on the past learning experiences, provides the adaptation of the learning environment, recommending the accomplishment of certain learning activities, collect opinions about a subject, suggest Web resources, alert the student for events, and give support in the agenda management.

\section{Conclusions}

The use of intelligent systems has several advantages in the support and personalization of elearning. The intelligent tutoring systems are typically used in computer-based training (CBT) and don't support the collaboration and cooperation like groupware and cooperative work technologies. We propose the adoption of a CBR agent in Adaptive Webbased Educational Systems.

The integration of agents with case-based reasoning methodology permits a more effective learning experience, adapting and personalizing the contents and contexts to the students needs.

The Domus agent supports the student in their learning activities, collaborative work, portfolio management, agenda management, and shows several points of view of some subjects, suggesting Web resources to complement the student knowledge.

\section{References}

[1] J. Kolodner, "Case-based Reasoning”, Morgan Kaufman, 1993

[2] C. Yang, "Applying collision avoidance expert system to navigation training systems as an intelligent tutor", Proceedings of IEA/AIE 14th International Conference, Budapest, Hungary, 2001, pp. 941-947

[3] A. Aamodt, and E. Plaza, "Case-based reasoning: Foundational issues, methodological variations, and system approaches", Artificial Intelligence Communications, 1994, pp. $39-59$

[4] G. Kearsley, "Artificial intelligence and education: Applications and methods", Addison-Wesley, 1987

[5] P. Brusilovsky, and M. Maybury, "From adaptive hypermedia to adaptive Web", Communications of the ACM, 2002, pp. 31-33 